\title{
Commentary
}

\section{Challenges and Opportunities for Health Research in Rajasthan}

\author{
Vishwa Mohan Katoch
}

\begin{abstract}
NASI-ICMR Chair on Public Health Research, Rajasthan University of Health Sciences, Jaipur. Former Secretary, Department of Health Research, Ministry of Health \&
\end{abstract} Family Welfare, Government of India \& Director General, Indian Council of Medical Research, New Delhi.

\section{INTRODUCTION}

Biomedical research involves "the investigation of biological process and causes of disease through careful experimentation, observation, laboratory work, analysis and testing". Compared with this health research has much broader scope of working on important related areas like, health systems research social sciences and health economics etc. Research in medical and allied sciences is not new for India. From ancient times a number of contributions have been made by Indians through keen observations.

During recent history, Indian Council of Medical Research (ICMR) has played key role in the evolution of medical and biomedical research in India. ICMR was created in 1911 and has grown as a science agency to provide leadership in biomedical research. ICMR is now a part of Department of Health Research (DHR) and has a larger canvas and access to state institutions. Department of Science and Technology (DST), Department of Biotechnology (DBT), Council of Scientific and Industrial Research (CSIR), Defense Research Development Organization (DRDO) and other science agencies have also been contributing in selected areas and aspects.

It is seen that most of projects undertaken being undertaken do not adopt a comprehensive approach, involving the process, issues related to host, parasite and environment, and are therefore incomplete. Regarding the health challenges, except for few conditions peculiar to desert like Crimean Congo
Hemorrhagic Fever (CCHF), nutritional deficiencies, extreme heat and other environmental effects and other health problems in Rajasthan do not appear to be different from other parts of India. Issues of access to adequate and timely availability of services are important for the state. When planning research studies or research career one needs to get broad view of national landscape as well as position of Rajasthan in this landscape of opportunities and challenges.

\section{GROWTH OF INDIAN STATE}

Successes and failures: Transformation of India into a modern developed nation has been by and large a success story. While the major challenge of equitable distribution of opportunities and facilities to all sections of our society is yet to be effectively tackled, our Institutions have grown \& various Government Science Agencies have made fair amount of investment into health research. Our health indicators though poor in some states, have overall improved very well almost reaching the western levels in many states. However, we need to remember that $30-40 \%$ of Indian population has health indices which are far below the desired and achievable levels. Rajasthan also needs to accelerate its efforts to achieve UN Millennium Development Goals (MDGs) and UN Sustainable Development Goals (SDGs). This indicates the needs to generate locally relevant knowledge for building a more robust health system and hard work is required in public health arena to reach all people.

History of innovations in health sector in India: A developed, progressive society produces and uses 
technology which takes care of its needs and also competes globally. Dhanwantri, Sushruta and Charaka are our legends in medicine and health. However, recent record of health related innovations in India is not inspiring and much more can be done to restore our national pride. It is often argued that domination of colonial civilizations stifled our originality. But then why no significant revival even after 70 years of independence? It is true that we are over-burdened with population, poverty, and disease load, but keen observations and scientific analysis was and is feasible. It is apparent that we have used our energies in reproducing what is done in the west and we usually do not innovate and pursue our needs. It is also observed that once our ideas and innovations are accepted internationally, they are then accepted in India. We take pride in being labelled under International banner and not as our own.

Indian products available in health sector: India ranks $2^{\text {nd }}$ (volume-wise) and $4^{\text {th }}$ (moneywise) globally in pharmaceutical manufacture and trade, especially in the generic sector. This sector was earlier protected by process patent. Indian institutions and industry has faced the transition to new patent regime very well. India dominates the vaccine industry globally, but more can be done by following the local leads and focusing on genetic/ epigenetic research. It is also heartening to note that India is fast emerging as a global hub of biotech industry. Major shortcomings are the lack of good and robust diagnostics and insignificant presence in indigenously developed medical equipment and micro-devices, thus these areas offer great opportunity to strengthen our leadership in pharmaceutical and device industry. Rajasthan has to create its niche on this front.

Excellence in designing treatment methods: In the present era of modern medicine, many Indian clinician researchers have excelled in designing effective treatment regimens with appropriate use of available drugs. Concepts of anti-tubercular therapy in DOTS and MDT in leprosy including new uniform regimen in leprosy have origins in India. There are several other examples in different branches of medicine and particularly in surgical disciplines. Several methods- more efficient, less time consuming, lesser hospital stay and with lesser post surgery complications have also been designed and are being fruitfully used in the population. However, it is usual that after others in West accept, our peers and policy makers later give recognition. This is a mind-set issue which has only one solution - producing more and more original work which will give confidence to doubting minds and activate our self respect related genes .

\section{CONTRIBUTIONS OF DIFFERENT SCIENCE AGENCIES IN TRANSLATION}

It is known that translation process has many levels starting with new leads from biological and behavioural research and ending up with usable products or processes. Many Indians- scientists, politicians, administrators and the common man, have nurtured dream of creating new knowledge, developing new molecules/ products for diagnosis and treatment in an affordable manner. Several science agencies such as DST, DBT, CSIR, ICMR, DHR, DRDO etc. have invested fairly well in basic and applied medical, biomedical and health research. Indian Council of Agricultural Research (ICAR) is focusing on production of adequate amount and right kind of food for proper nutrition evolving in the context of climate change and also partnering with ICMR on control of zoonotic diseases. Departments of Atomic Energy, Department of Space, Department of Information Technology and other user ministries such as Women and Child Development, Environment and Forests, Rural Development, etc., are providing and are willing to provide their collaborative support.

Translational research at ICMR: ICMR has established a system of fostering translational research. Twenty-six translational research cells were established during 2009-2010 at ICMR Institutes and Centres. A translational research cell has also been established at ICMR headquarters which coordinates programmes of ICMR's Institutes and Centres under translational research and assists in carrying forward their technologies for implementation. To start with, 
one hundred and two (102;52 in first phase) technologies and / or programmes were identified and pursued. Of these, eight technologies were released during the years 2013-2015 and another dozen are ready. Technologies released include diagnostic methods for diabetes, thalassemia and sickle cell anaemia, Kala-Azar, a device for screening for cervical cancer, detection of food borne methods, methods for estimation of vitamin A as well as ferritin etc. It is beginning of the translational process and many more products are expected in future.

Department of Scientific and Industrial Research and Council of Scientific and Industrial Research: CSIR laboratories have developed several drugs for the treatment of tuberculosis, malaria, leishmaniasis, diabetes mellitus, clot-busters and others. Anti-fertility drugs developed by CSIR have already earned a good name. CSIR institutions are contributing on vital areas like toxicology, phytomedicine etc. Products from CSIR are available for fertility control. Several devices and appliances from CSIR are also ready. Open Source Drug Discovery (OSDD) programme of CSIR has established several new leads; one has already entered clinical trials against tuberculosis.

Department of Biotechnology (DBT): The Department of Biotechnology (DBT) has made a major impact on the development of biotechnology related products for health care as well as other sectors. Several diagnostics, vaccines and other health care products have been developed with financial support from DBT, Creation of Translational Health Research Institute at Gurgaon, Haryana is a landmark. Several other programmes of DBT are changing the Indian landscape. DBT has several institutions in selected areas- genomics, stem cells, genetic engineering, immunology, diagnostics, DNA fingerprinting etc., which are working on biomedical research.

Department of Science and Technology (DST): DST, the umbrella science agency in India, funds biomedical research, both basic and applied, in a significant manner. Areas include those pertaining to infectious and non-communicable diseases. DST funded research has influenced almost all facets of medical sciences. Many leads from this research including newer areas such as nanotechnology have been available for quite some time. It is also supporting state DST's which have become quite active in some states.

Defense Research and Development Organization (DRDO): DRDO continues to contribute not only to self reliance in products related to defence but also for areas such as health. DRDO institutions have developed several methods for diagnosis of infectious diseases, bioremediation, vector control as well as more nutritious alternate foods. Good affordable equipment such as ventilators, bio-toilets etc., have been developed by DRDO laboratories. Several products for treatment of poisoning, wounds, heat or cold stress management, etc., have been developed by DRDO which also funds research in civilian institutions in areas of common interest.

Other science agencies and health research: Several other ministries- Departments of Atomic Energy, Space, Information Technology, Department of Environment and Forests and several others are contributing to health research related areas. Coordination mechanisms have been established through Department of Health Research (DHR) and areas for joint action have been identified and some actions already initiated. We can anticipate their impact in future. More co-ordination efforts and better synergy is required among Indian Institutes of Technology, Information Technology Institutes and medical experts for achieving better output.

Human resources: Over the years there has been increase in the investments by many fold by science departments and also by the industry but this has not led to parallel increase in the output because of lack of adequate and properly trained human resource. Human resource specially those having inter-disciplinary expertise appears to be the major limiting factor. Faculty from medical colleges is not adequately involved in research and has to be targeted for their 
involvement. Our scientific community usually likes to investigate scientifically interesting or glamorous ideas rather than spend time on developing new tools which may benefit the masses and also contribute to economic prosperity. Large number of leads remains lying in the heap of "new unutilized knowledge". Stakeholders including individuals, science departments, University Grants Commission (UGC), Ministry of Human Resource development (MHRD), States and NGO's need to address this issue

Roadblocks at national level: Mindset of user community specially the middle class as well as our medical fraternity are major factors hindering industrial and biomedical research. Regulatory structure and processes have improved but have not been able to keep pace with the changing needs. There are very few laboratories, either in the Government or private sector that could quickly provide either samples or carry out independent evaluation of products developed. Inadequate support to clinical trials especially comparative studies requires corrective measures; further various Indian players lacking resources are only partially responsible for slow progress. Several agencies like DBT, DRDO, ICMR/ DHR, CSIR etc., have invested heavily in research aimed at translation for health. Better coordination and user-friendly regulatory system can certainly enhance the productivity even under the present situation.

\section{POSITIVE DEVELOPMENTS}

Recent examples: DBT and ICMR/ DHR have invested significantly towards the creation of dedicated institutes, set-ups and multi-disciplinary research units in medical colleges' rural units on translation and created a grand vision for translation in this country. DST is also significantly supporting the process. Political commitment and administrative action was visible and success was tasted in terms of indigenously developed vaccines and diagnostics when facing H1N1 pandemic. Market demands creation of facilities like clinical research organizations
(CRO's). Such organizations have come up but it is not happening in all the sectors, and this is important. It appears that indigenous innovation does not have adequate interest of market forces at this moment of time. Things are changing for the better but we still have miles to go.

Strengthening research in medical colleges and relevance to Rajasthan: DHR has launched three schemes during 2013-14 to strengthen the research in state medical colleges and government institutions.

- Multi-disciplinary Research Units (MRUs): This scheme has been approved to establish 80 Multidisciplinary Research Units (MRUs) in state government medical colleges to create a dedicated infrastructure for research in medical colleges with special focus on non-communicable diseases (NCDs), genetics, mother and child-health, mental health and translation research.

- Model Rural Health Research Units (MRHRUs): This scheme has been launched to establish 15 units in different states initially and is based on successful experience of ICMR at Ghatampur (UP). This tripartite model (ICMR, State medical college and state health service) aims at transfer of technology for early diagnosis and management of various diseases for the benefit of rural population.

- Establishment of Network of Virus Diagnostic Research Laboratories (VDRLs): This scheme aims at establishment of 160 units (10 regional centers, 30 state and 120 medical college level laboratories) to strengthen clinical, therapeutic and epidemiological research on viral diseases.

The ICMR has 33 national/ regional institutes/ and/or centres and 111 field units dedicated to biomedical research. This ICMR system is serving as a fulcrum to activities of DHR. Other schemes of DHR for human resource development and grant-in-aid support this empowerment. Out of target of 255 MRUs, Model RHRU and Virology Research and Diagnostic (VRDL) units till end of 2017, 115 have already been sanctioned and mostly established/ getting established. 13 units have already been approved for Rajasthan that include 6MRUs, 6 VDRLs and one MRHRU. Nearly half of 
them are already function, others are in different stages of development. One Regional VDRL has been planned at Jodhpur for westem India.

Rajasthan has a large number of medical colleges mostly in public as well as a few in private sector. Many new medical colleges are expected to come up in near future. AIIMS, Jodhpur has become functional. It has an ICMR Institute at Jodhpur (Desert Medicine Research Centre) which is making efforts to network medical colleges, universities and ICAR/ other institutions for a cohesive and synergistic action on several health challenges like silicosis, nutritional problems, mother and child health, NCDs, malaria, genetic disorders and tribal health etc. Institutions like IIHMR are providing leadership to health management research.

Rajasthan University of Health Sciences (RUHS) is encouraging and supporting research in its affiliated institutions by creating institutional mechanisms of empowerment and financial help in terms of start up grants. There are a large number of other central Indian and alternate systems of medicine), dental, pharmacy, nursing and paramedical institutions which can and should contribute in health research.

Besides some important national agencies mentioned/ discussed in this article, there are several other national and international agencies (US National Institutes of Health, WHO, and many others) which can be approached for funding support. All depends upon having focus on research, properly defining the targets, charter a path, creating networks and improving and strengthening the mechanisms for better ecosystem for health research which will provide evidence for action in Rajasthan, at national level and will also improve the visibility at global level.

\section{WHERE DO WE STAND?}

We need to be realistic and truthful about ground realities, after 70 years of independence:

- Are we marching towards self-reliance in the areas of original local knowledge and needs, indigenous health care technologies suited to the needs and ecosystem of rural India and other similarly placed populations elsewhere?

- Have we begun our march and gaining desired momentum? Or is it merely a Flag March, which we do occasionally, to show our capability but then sleep comfortably afterwards?

- The truth is- we have demonstrated our capabilities whenever the occasion arose, but a sustained action in a desirable ecosystem has yet to build up. Like other states of India, Rajasthan has many well known individuals, some reputed institutions but has capacity to produce several fold better output if ecosystem is created with targeted approach on health research.

Make in India campaign can be used to strengthen both indigenous development and manufacture in India with Rajasthan playing its chosen role.

\section{FUTURE}

This write-up only provides an overview of challenges and opportunities. Issues and opportunities are not exhaustive but illustrative. Accessing websites of various agencies will provide up to date information about their current priorities and funding opportunities. Research targets are to be chosen after careful review of data on different health conditions in the state, identify limitations and gaps in knowledge, identifying niche areas for innovation and industrial development in the context of biomedical and health research.

While we certainly need more resources dedicated to health research at national and state level, Rajasthan can have a better output even under the present conditions. We should remember that research is not separate from patient care and research. It is a fuel to drive the march towards better patient care, better teaching and training and stronger public health action. We need to commit ourselves to target and achieve something concrete in socially relevant areas - that itself will drive the change towards betterment in all spheres including biomedical and health research. 